\title{
INTELIGÊNCIA ARTIFICIAL E DIREITO DE AUTOR: TECNOLOGIA DISRUPTIVA EXIGINDO RECONFIGURAÇÃO DE CATEGORIAS JURÍDICAS
}

\author{
Fernanda Borghetti Cantali ${ }^{1}$
}

Resumo: A inteligência artificial é uma das novas tecnologias disruptiva que vem provocando uma mudança profunda no modo de ser da sociedade em escala global. O tema traz em si um dos desafios postos no contexto da anunciada quarta revolução industrial. O direito não escapa dos impactos da inteligência artificial que, a princípio, emula o ser humano, mas já caminha para o aprendizado autônomo. Já existem diversos exemplos de músicas, poesias, pinturas criadas por inteligências artificiais. Nesse contexto, é imprescindível discutir a questão da autoria destas obras. Admitir a autoria maquínica exigirá reconfiguração dessa categoria jurídica.

Palavras-chave: Tecnologia; Disrupção; Colaboração; Inteligência Artificial; Autoria.

\section{ARTIFICIAL INTELLIGENCE AND COPYRIGHT: DISRUPTIVE TECHNOLOGY AND THE NEED TO RESTRUCTURE LEGAL CATEGORIES}

\begin{abstract}
The artificial intelligence is one of the new disruptive technologies that has been causing a profound change in the way of life of human society on a global scale. The subject brings in itself one of the challenges set in the context of the announced fourth industrial revolution. The law is not free from the impacts of artificial intelligence, which at first emulated human beings, and now moves toward self-learning. There are several examples of songs, poems and paintings created by artificial intelligence. In this context, it's essential to discuss about authorship of these works. Recognizing machine authorship will require restructuring this legal category.
\end{abstract}

Keywords: Technology; Disruption; Collaboration; Artificial Intelligence; Authorship.

\footnotetext{
1 Advogada. Doutoranda em Direito pela UNISINOS. Mestre em Direito pela PUCRS. LLM em Direito Empresarial pelo CEU Law School. Professora de Direito Empresarial e de Direito da Propriedade Intelectual da UNISINOS e da ESMAFE - Escola Superior da Magistratura Federal. Pesquisadora do grupo Inteligência Artificial e Inclusão do ITS RIO. E-mail: fernandaborghetti@hotmail.com
} 


\section{INTRODUÇÃO: APRESENTANDO RISCOS E POSSIBILIDADES}

A Inteligência Artificial, ou simplesmente IA, já não faz parte apenas do imaginário científico; faz parte do dia a dia das pessoas. A grande maioria ainda não possui uma efetiva compreensão sobre o tema, mas, no mínimo, existem os que se posicionam de forma favorável ou contrária a sua utilização. O tema implica em extremos. E estes extremos não são particularidades daqueles que ainda não refletiram sobre o assunto ou acham - sim, acham ${ }^{2}-$ que ainda não foram afetados por tal tecnologia. Discussão acalorada abala o Vale do Silício desde o ano passado. Elon Musk, fundador do PayPal, CEO da Tesla Motors e da empresa aeroespacial SpaceX, entende que a IA sem regulamentação é uma ameaça para a civilização. Diametralmente oposta é a opinião de Mark Zuckerberg o qual é muito otimista sobre o uso da IA, sustentando que ela é feita e controlada por seres humanos e pode ser utilizada para o bem ou para o mal, como toda a tecnologia. Embora os dois gigantes estejam trocando farpas publicamente, fato é que o assunto precisa ser efetivamente debatido.

Pensando nas possibilidades que a IA pode implicar, traz-se o exemplo do computador cognitivo Watson da IBM. Este sistema, por exemplo, permite que um médico possa ler cinco mil novos estudos por dia e ainda visitar seus pacientes, que um analista de tecnologia da informação possa analisar um milhão de eventos de segurança a cada segundo, sessenta vezes mais rápido do que o faria sem IA; que os gerentes de logística possam antever contratempos e gerenciar transações em cadeia de suprimentos que abrangem milhares de quilômetros, reduzindo custos e melhorando eficiência, bem como empresas e prestadores de serviço possam responder trinta e três mil perguntas a diferentes trinta e três mil clientes ao mesmo tempo. (DE MÃOS, 2017). Por outro lado, pensando em automação, Federico Pistono (2017), um

\footnotetext{
${ }^{2}$ Muitas pessoas creem que a IA ainda não faz parte de suas vidas. Mas basta questionar quem tem o hábito de utilizar o Google. O mais famoso site de busca deste planeta é estruturado em uma plataforma de IA, seja para seleção de conteúdo quando se pesquisa uma palavra, seja para a tradução de uma língua para outra. Outro exemplo é o Facebook que oferece posts selecionados especialmente ao seu usuário através do uso de algoritmos programados para entender o gosto particular de cada um. Sem falar em assistentes virtuais como a Siri que vem instalado em qualquer telefone móvel da Apple. Não há nada mais fantástico que o Google. É simplesmente "alguém" para quem você pode questionar o que quiser e o que tiver interesse. Ele sempre terá uma resposta. Por outro lado, como o tema traz sempre dois lados, é importante lembrar a obra "o filtro invisível" de Eli Parisier (2012) que alertou para a bolha dos filtros. O autor demonstrou que, a partir da navegação de cada usuário na web, gigantes como Google, Facebook, Apple e Microsoft criam filtros formados por algoritmos que personalizam o resultado das buscas na internet. Exemplifica dizendo que se duas pessoas fizerem exatamente a mesma pesquisa, os resultados serão diversos, já que direcionados para o interesse de cada um dos usuários, o que é possível, obviamente, pelo uso da inteligência artificial. Afirma o autor que o risco destes filtros é provocar um confinamento das pessoas em um universo pessoal único de informações. Contudo, explica o que cada um de nós, assim como as empresas, pode fazer para tornar a web mais democrática.
}

Rev. de Direito, Inovação, Propriedade Intelectual e Concorrência | e-ISSN: 2526-0014 | Porto Alegre | v. 4 | n. 2 | p. 1 - 21 | Jul/Dez. 2018 
pesquisador italiano da ciência da computação, afirma que os robôs vão roubar o trabalho das pessoas. Sustenta que se as pessoas desejam ter algum tipo de segurança em relação aos próximos anos, precisam aprender a programar computadores, trabalhar com criptografia ou com IA. ${ }^{3}$ Pistono, encarando os impactos das novas tecnologias sobre o trabalho e a sociedade, a partir de uma perspectiva sistêmica global, sustenta que se a automação vai provocar desemprego em massa, as pessoas precisarão reduzir sua dependência do sistema. Mas, em contrapartida, a automação também provocará o aumento da produção, reduzirá seus custos e, assim, as coisas, em tese, custarão menos. Mas, buscando uma visão otimista, entende que a revolução propiciada pela IA provocará mudanças nas estruturas sociais e de poder, bem como que será a grande chance que a humanidade terá de repactuar o convívio em sociedade, tornando efetivo o termo colaboração, mudando também sua relação com o próprio Estado. ${ }^{4}$

Não se tem nenhuma dúvida de que as novas tecnologias vêm impactando a sociedade, a economia, as pessoas de forma individual, assim como está a exigir a reconfiguração de determinadas categorias jurídicas. Moeda digital, contratos inteligentes, robôs substituindo os humanos nas mais diversas tarefas já são realidade.

Muitas são as perspectivas de análise da temática da inteligência artificial, mas como forma de delimitação para o presente artigo optou-se por tratar do seu impacto no âmbito do direito autoral, área afeta ao direito da propriedade intelectual. $\mathrm{Na}$ atualidade, muitas pessoas utilizam sistemas de inteligência artificial para criação de obras, sistemas estes que não são mais utilizados apenas como instrumentos, mas atuam colaborativamente, ou até mesmo de forma autônoma. É possível falar em obra decorrente da colaboração entre homem e máquina? É possível falar em autoria maquínica?

Para o enfrentamento do objetivo geral do presente artigo, refletido nos problemas acima postos, tem-se também a necessidade de contextualizar a temática e fazer a delimitação

\footnotetext{
${ }^{3}$ Ocorre que poucas pessoas possuem estas habilidades, porque o cérebro humano não foi estruturado para o desenvolvimento de tais habilidades. $\mathrm{O}$ homem atual desenvolveu outras habilidades que, embora valiosas, não possuem relevância para o novo mercado que está em formação.

${ }^{4}$ Aliás, as relações de trabalho se modificam ao longo da história da sociedade. Isso fica muito claro quando se compara o trabalho industrial do início do século XX com a nova forma de trabalho, o pós-industrial, caracterizado por um trabalhador com múltiplas habilidades e capacidades intelectuais em detrimento da força física, o qual é resultante de mudanças sociais decorrentes do aumento da quantidade de trabalhadores no setor de serviços, da necessidade de interação com os clientes e/ou consumidores, dos aspectos emocionais envolvidos nesta interação, além de questões de estilo e estética. Estas mudanças geraram um novo tipo de trabalhador como profissional do conhecimento, empreendedor de si e de suas tarefas. (EDGELL, 2012) Com alguma controvérsia, esse tipo de trabalho também tem sido chamado de imaterial, conforme a teoria desenvolvida principalmente por Maurizio Lazarratto e Antônio Negri (2001). Será que, a partir do uso da IA, uma nova forma de trabalho não deverá ser delineada? Afinal, haverá trabalho desenvolvido pela interação do homem e da máquina, mas também exclusivamente pelas máquinas.
} 
de determinadas premissas básicas para a compreensão do tema, tais como: discutir sobre a quarta revolução industrial, avaliar quais são as novas tecnologias que causam maior disrupção, explicar o que é inteligência artificial, apresentar a definição de autor conforme a disciplina legal brasileira e indicar as principais reflexões que precisam ser travadas no âmbito da propriedade intelectual, mais especificamente no âmbito do direito de autor para a necessária reconfiguração de determinadas categorias jurídicas.

No que toca aos instrumentos metodológicos, procura-se sempre realizar uma abordagem pragmático-sistêmica, o qual possibilita a conexão e estruturação de modelos autorregulatórios, buscando a interligação com conhecimentos oriundos de outras ciências. A observação correrá principalmente a partir do acompanhamento do Direito, mas em um contexto interdisciplinar. Ou seja, parte-se de uma análise da sociedade e, a partir desta, para a análise do Direito como um subsistema imerso no sistema social, ou um sistema inserido no meio, no seu entorno. (LUHMANN, 1983).

Além da necessidade interdisciplinar que o próprio tema da pesquisa impõe, vê-se que há uma demanda metodológica mundial pela interdisciplinaridade, exigindo-se o trabalho conjunto de cientistas, ao ponto de a Revista Nature (2015) afirmar que os cientistas precisam sair de sua zona de conforto para, colaborativamente, "salvarem o mundo".

Por fim, segundo seus objetivos a pesquisa será exploratória, em relação à coleta de material e fontes de informação a pesquisa é basicamente bibliográfica e documental. Além disso, serão utilizados casos concretos, todos os dias noticiados em meios de comunicação como jornais, revistas e na própria internet. Afinal, o tema da IA implica em aliar o mundo jurídico ao contexto empírico e de outras ciências, o que exige uma metodologia mais flexível e adaptável a uma nova realidade anunciada pela quarta revolução industrial: o mundo digital em força total.

\section{INOVAÇÃO E DISRUPÇÃO: NOVAS TECNOLOGIAS E O CONTEXTO DA QUARTA REVOLUÇÃO INDUSTRIAL}

Em 1976 a Kodak possuía 90\% do mercado de equipamentos fotográficos, profissionais e amadores. Em 1984 esta empresa possuía cento e quarenta e cinco mil empregados. Em 2012 a empresa contabilizou prejuízo de um bilhão de dólares e sucumbiu. O que aconteceu? Seus gestores falharam em prever a importância de tendências exponenciais quando se trata de tecnologia.

Rev. de Direito, Inovação, Propriedade Intelectual e Concorrência | e-ISSN: 2526-0014 | Porto Alegre | v. 4 | n. 2 | p. 1 - 21 | Jul/Dez. 2018 
No mesmo ano, em 2012, o Instagram, empresa de fotografa digital, contava apenas com treze empregados e foi vendida para o Facebook por um bilhão de dólares. Todos conhecem esta história. Mas o mais paradoxal é que a Kodak foi a empresa pioneira na tecnologia de fotografia digital, lançando a primeira câmera digital em 1975. Contudo, os gestores entenderam que a câmara digital era um brinquedo e não deram atenção para ela. (KLEINA, 2017).

Nicholas Negroponte (1995) publicou a obra "Vida Digital" e afirmou em suas passagens conclusivas:

\footnotetext{
Os bits não são comestíveis; nesse sentido, não são capazes de acabar com a fome. Os computadores, por sua vez, são amorais: não podem resolver questões complexas como as do direito à vida e à morte. Não obstante, a vida digital é algo que oferece muitos motivos para o otimismo. Assim como uma foça da natureza, a era digital não pode ser negada ou detida. Ela dispõe de quatro características muito poderosas, as quais determinarão o seu triunfo final: a descentralização, a globalização, a harmonização e a capacitação.
}

Nem parece que o local de fala do autor tem mais de vinte anos, tal a sua atualidade. $\mathrm{O}$ efeito descentralizador da vida digital se manifesta de forma muito significativa no âmbito das corporações, as quais precisam se reinventar todos dos dias para fazer frente às novas possibilidades geradas pelas inovadoras tecnologias levadas a efeito e potencializadas pela imensa capacidade criativa dos homens.

A vida digital também impacta na noção de Estado que, afetado pela globalização, parece maior e menor ao mesmo tempo, chegando-se na noção de transnacionalidade. Nesse ponto, merece destaque também os estudos realizados por Gunther Teubner (2016), para quem é necessário sedimentar a ideia de uma Constituição e um constitucionalismo que se encontra, também, além do Estado. É possível constitucionalizar em setores privados. Teubner sustenta a existência de uma Constituição Digital, não estatal, única capaz de dar conta das questões no ambiente digital absolutamente descentralizado e globalizado.

Do ponto de vista da harmonização, a vida digital propiciou o desenvolvimento de uma linguagem comum, a qual permite que pessoas se entendam independente das fronteiras. E não é só isso, a competição entre pares cedeu em prol da colaboração. E ainda, a vida digital traz em si uma capacidade de produção de mudança jamais vista. Mudanças que ocorrem no seio da sociedade e que provocam o delineamento de novos direitos ou de novos sentidos hermenêuticos para categorias existentes. 
A sociedade vem enfrentando os efeitos do chamado fenômeno da disrupção digital. Disrupção é termo cunhado pelo Professor de Harvard Clayton Christensen (1995) e foi utilizado para descrever inovações que oferecem produtos ou serviços que criam um novo mercado e, assim, desestabilizam os concorrentes que antes o dominavam. Geralmente são mais simples e mais baratos do que o que já existe ou algo capaz de atender o público que antes não tinha acesso a determinado mercado. Modelos de negócios disruptivos iniciam atendendo um público restrito e, na sequência, acabam conquistando todo o segmento. ${ }^{5}$

$\mathrm{O}$ caso das câmeras digitais, antes noticiado, se encaixa perfeitamente nesse fenômeno. Tal tecnologia, num primeiro momento, foi ignorada, principalmente pelos fotógrafos profissionais, os quais alegavam que a qualidade da foto era ruim. Mas as câmeras digitais ganharam a simpatia de fotógrafos amadores até substituírem completamente a tecnologia mais antiga. Hoje os dispositivos eletrônicos já fazem o reconhecimento facial de seus proprietários. O iPhone X da Apple, através do reconhecimento facial, recebe comandos de destravamento, por exemplo. Fascinante? Sim, mas esta mesma tecnologia foi aplicada em fotos digitais e apresentou capacidade de identificar qual a opção sexual do retratado, ou ainda pior, identificou pessoas negras como gorilas. (HARADA, 2015). Ou seja, a mesma tecnologia que traz um serviço útil, afronta à intimidade das pessoas ou se apresenta preconceituosa. ${ }^{6}$ Aliás, os avanços tecnológicos acabam sempre impactando em direitos fundamentais individuais tais como a intimidade, a privacidade e a vida privada. Questão que de longa data preocupa juristas é justamente a proteção dos dados pessoais ${ }^{7}$. (DONEDA, 2006). Mais ainda hoje na era do Big

\footnotetext{
${ }^{5}$ O termo apareceu pela primeira vez em um artigo, de 1995, intitulado "Disruptive Technologies: Catching the Wave". Depois, Clayton Christensen desenvolve melhor sua teoria nas obras: The Innovator's Dilema e The Innovator's Solution. Boston: Harvard Business Review Press.

${ }^{6}$ Caso famoso no mesmo sentido foi o da @ TayandYou, um perfil no Twitter criado pela Microsoft, baseado em IA, que se destinava, por meio de algoritmos, a aprender e aumentar seu vocabulário e interagir com adolescentes. Apesar de conseguir 70 mil seguidores rapidamente, o perfil ficou no ar menos de 24 horas, porque a Tay rapidamente publicou tweets racistas, homofóbicos e nazistas. A Microsoft desligou o perfil para "fazer ajustes" em sua IA. Para maiores informações, acessar o link: https://www.tecmundo.com.br/inteligenciaartificial/102782-tay-twitter-conseguiu-corromper-ia-microsoft-24-horas.htm.

${ }^{7} \mathrm{O}$ tema da proteção de dados recebeu destaque no ano de 2018 com a entrada em vigor do Regulamento Geral sobre a Proteção de Dados da União Europeia - GDPR, que estabelece regras relativas ao tratamento, por uma pessoa, uma empresa ou uma organização, de dados pessoais relativos a pessoas na União Europeia. As regras não se aplicam ao tratamento de dados por motivos exclusivamente pessoais ou no exercício de atividades domésticas, desde que não haja qualquer ligação com uma atividade profissional ou comercial. Quando uma pessoa utiliza os dados pessoais fora da sua esfera pessoal, por exemplo, para o exercício de atividades socioculturais ou financeiras, a legislação relativa à proteção de dados tem de ser respeitada. Para aprofundamento, vide o Manual da legislação Europeia sobre proteção de Dados, disponível no link: https://www.echr.coe.int/Documents/Handbook_data_protection_POR.pdf. Menos de dois meses depois da entrada em vigor do GDPR, o Congresso Nacional brasileiro aprovou a Lei Geral de Proteção de Dados (PLC 53/18). Parece ser uma iniciativa positiva, já que o Brasil encontrava-se na lista dos países sem regulação específica para proteção de dados pessoais. Para analisar o mapa mundi de proteção de dados e a situação Brasileira, vide: https://www.nexojornal.com.br/expresso/2016/11/28/Qual-a-situa\%C3\%A7\%C3\%A3o-do-Brasil-no-mapa-de-
}

Rev. de Direito, Inovação, Propriedade Intelectual e Concorrência | e-ISSN: 2526-0014 | Porto Alegre | v. 4 | n. 2 | p. 1 - 21 | Jul/Dez. 2018 
Data, caracterizada pela grande qualidade de dados coletados e armazenados pelo uso de dispositivos eletrônicos ou digitais, conectados na rede mundial de computadores.

As empresas de tecnologia estão sempre na corrida para desenvolver inovações disruptivas. A aposta da Intel é na internet das $\operatorname{coisas}^{8}$, ou seja, na comunicação entre objetos pela rede mundial de computadores. Aliás, o tema da internet das coisas está totalmente ligado com a questão da proteção de dados pessoais. Eduardo Magrani (2018a, p. 20), em obra pioneira sobre o tema no Brasil, define internet das coisas

como um ambiente de objetos físicos interconectados com a internet por meio de sensores pequenos e embutidos, criando um ecossistema de computação onipresente (ubíqua), voltado para a facilitação do cotidiano das pessoas, introduzindo soluções funcionais nos processos do dia a dia.

O professor adverte que existem fortes divergências sobre a definição de IoT - internet of things -, mas todos elas comungam que o seu foco está em "como os computadores, sensores e objetos interagem uns com os outros e processam informações/dado em um contexto de hiperconectividade”. (MAGRANI, 2018a, p. 20). Na medida em que estes aparelhos conectados na internet coletam toda a sorte de dados das pessoas, revelando até mesmo propensões a doenças, hábitos diários, o que é facilmente perceptível por aqueles que usam tecnologias vestíveis, os conhecidos wearables, há necessidade de um design ético. Como toda nova tecnologia, traz em si aspectos positivos e outros negativos. (MAGRANI, 2018a). ${ }^{9}$

Várias são as tecnologias que estão impactando a vida social e negocial das pessoas, gerando inclusive uma série de novos modelos de negócios. Quem não foi surpreendido com a criação do transporte compartilhado e com a hospedagem em nova perspectiva? Além de uma maior adequação das necessidades dos consumidores, tais modelos propiciam serviços com

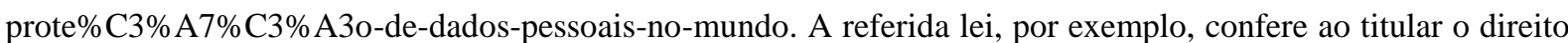
de solicitar uma revisão de decisões tomadas exclusivamente com base em tratamento automatizado, ou seja, pelo uso de IA. Pode-se dizer que a aprovação da lei representa um avanço, principalmente por desvincular o uso restrito do Marco Civil da Internet para o tratamento de questão que merece maior amplitude, contudo, trata algumas dificuldades que deverão ser enfrentadas, como, por exemplo, quando o direito à explicabilidade esbarrar na propriedade intelectual alheia e/ou no segredo industrial de uma empresa. Vide também: https://www.nexojornal.com.br/expresso/2018/06/07/O-que-diz-o-projeto-de-lei-de-prote\%C3\%A7\%C3\%A3ode-dados-que-tramita-no-Senado.

8 É o que se pode perceber pela proposta apresentada no site da companhia. Disponível em: https://software.intel.com/pt-br/iot/home, acesso em 28 de outubro de 2017.

${ }^{9}$ Importante mencionar que, objetivando promover o desenvolvimento sustentável e competitivo da economia brasileira, o BNDES, em parceria com o Ministério da Ciência, Tecnologia, Inovações e Comunicações (MCTIC), apoiou a realização de um estudo para o diagnóstico e a proposição de plano de ação estratégico para o país em Internet das Coisas. $\mathrm{O}$ relatório do plano de ação está disponível na internet pelo link: https://www.bndes.gov.br/wps/wcm/connect/site/269bc780-8cdb-4b9b-a297-53955103d4c5/relatorio-finalplano-de-acao-produto-8-alterado.pdf?MOD=AJPERES\&CVID=m0jDUok.

Rev. de Direito, Inovação, Propriedade Intelectual e Concorrência | e-ISSN: 2526-0014 | Porto Alegre | v. 4 | n. 2 | p. 1 - 21 | Jul/Dez. 2018 
menor custo, na maioria das vezes, para uma das partes, e oportunidades de renda e trabalho para a outra parte.

Outra tecnologia que traz ruptura é a robótica e o uso de drones. Estes já fazem parte da realidade para filmagens e fotografias aéreas, mas logo serão responsáveis por entregas postais e até mesmo para o transporte de pessoas. Sem falar na robótica em si, a qual se insere nos mais diversos segmentos, até naqueles inimagináveis como na área da saúde para realização de cirurgias, e na advocacia em que o Ross, um robô da IBM com base na tecnologia de computação cognitiva Watson, realiza tarefas antes exclusivas dos advogados, como contratos e prazos, e já divide opiniões. (ATENIENSE, 2017; FERNANDES, 2017; GENTILE, 2017).

A realidade virtual também é outra façanha, precedida da realidade aumentada pelos óculos 3D, hoje já se permite através dela uma imersão total no mundo digital permitindo aos consumidores novas experiências que vão desde viagens, jogos ou até a aquisição de um imóvel. Em voga também anda a tecnologia blockchain que permite uma maior segurança nas transações digitais e serve de base para a distribuição do bitcoin, a moeda virtual que tem potencial para ser a única fonte de valor monetário para negociações na internet, o que impactaria de maneira profunda instituições financeiras e seus protocolos, como defende Pistono (apud SÔNEGO, 2017).

Ainda, a inteligência artificial, juntamente com a computação quântica. A inteligência das máquinas também já é uma realidade, as quais apresentam uma capacidade de interagir em situações e contextos, se aproximando da capacidade dos seres humanos de pensar, ou até mesmo superando-a dada a velocidade e precisão com que irão exercer sua capacidade intelectiva. A IA, que será levada ao desenvolvimento máximo quando do uso do computador quântico, este mais eficiente ainda na resolução dos algoritmos, trará um imenso incremento na produtividade.

Internet das coisas, big data, tecnologia vestível, drones, impressora 3D, robótica, carros autônomos, nanotecnologia, moedas digitais, blockchain e a não menos importante IA são algumas das tecnologias revolucionárias que estão impactando os indivíduos, as organizações, os governos e a sociedade. Mas, conforme Klaus Schwab (2016), a inteligência artificial e o aprendizado das máquinas em conjunto com uma internet mais ubíqua e móvel, consubstanciada em sensores menores e mais poderosos marca de forma indelével o início de uma quarta revolução industrial, a qual teve início na virada do século e baseia-se na revolução

Rev. de Direito, Inovação, Propriedade Intelectual e Concorrência | e-ISSN: 2526-0014 | Porto Alegre | v. 4 | n. 2 | p. 1 - 21 | Jul/Dez. 2018 
digital, marca da terceira revolução industrial ${ }^{10}$. Esta estava ligada com o fenômeno da computação e culminou com o advento da internet. Mas hoje este mundo digital iniciado com a terceira revolução está começando a viver em força total:

\begin{abstract}
As tecnologias digitais, fundamentadas no computador, software e redes, não são novas, mas estão causando rupturas à terceira revolução industrial; estão se tornando mais sofisticadas e integradas e, consequentemente, transformando a sociedade e a economia global. Por este motivo, os professores Erik Brynjolfsson e Andrew McAfee do Massachusetts Institute of Technology (MIT) disseram que este período é "a segunda era da máquina", no título do livro publicado por eles em 2014; estes dois professores afirmam que o mundo está em um ponto de inflexão em que o efeito dessas tecnologias digitais irá se manifestar com "força total" por meio da automação e de "coisas sem precedentes". (SCHWAB, 2016, p. 16).
\end{abstract}

Estas novas tecnologias trazem ruptura social e jurídica. Não há como o Direto ficar alheio as transformações. As tecnologias de ruptura estão a exigir reconfiguração de muitas categorias jurídicas. Do ponto de vista do Direito da Propriedade Intelectual, o impacto destas novas tecnologias é imenso. Não só no sentido de a propriedade intelectual responder aos seus desafios, mas pelo simples fato de que a propriedade intelectual é o centro de toda a proteção que se dispensa para a inovação.

\title{
3. INTELIGÊNCIA ARTIFICIAL E ROBÔS HUMANOIDES: SEPARANDO O JOIO DO TRIGO
}

Antes de adentrar ao tema do impacto da inteligência artificial no âmbito da propriedade intelectual e mais especificamente no que toca ao direito de autor é preciso defini-la e fazer algumas distinções necessárias para auxiliar na compreensão do tema.

Quando se fala em IA se pensa na possibilidade de robôs realizarem, de forma inteligente, tarefas cotidianas e profissionais, que outrora eram realizadas exclusivamente por seres humanos. A Canon, só para continuar no âmbito do mesmo mercado do exemplo da Kodak, é uma empresa que vem apostando em automação e, nesse projeto vem substituindo o

\footnotetext{
${ }^{10}$ A primeira mudança profunda na maneira de viver se deu com a revolução agrícola, quando o homem deixou de ser um mero catador e começou a produzir os seus alimentos, dominando a agricultura. Esta revolução, que ocorreu a cerca de 10.000 anos, foi seguida por uma série de revoluções industriais, iniciadas na segunda metade do século XVIII. A primeira revolução industrial foi provocada pela construção de ferrovias e pela invenção da máquina a vapor. Foi aquela que deu início a produção mecânica. A partir do final do século XIX, com o advento da eletricidade e da linha de montagem, possibilitou-se a produção em massa, o que caracterizou a segunda revolução industrial. A terceira revolução industrial teve início na década de 60 e foi chamada de revolução digital. Esta foi impulsionada pelo desenvolvimento dos semicondutores, da computação em mainframe (1960), da computação pessoal (1970/80) e da internet (1990). Para aprofundamento e análise dos impulsionares e impactos da quarta evolução industrial ver a obra "A quarta revolução industrial” de Klaus Schwab.
}

Rev. de Direito, Inovação, Propriedade Intelectual e Concorrência | e-ISSN: 2526-0014 | Porto Alegre | v. 4 | n. 2 | p. 1- 21 | Jul/Dez. 2018 
trabalho humano pelo trabalho de robôs, os quais são muito mais rápidos e eficientes, incrementando sua produtividade.

Trata-se de uma inteligência similar à humana exibida por mecanismos ou softwares. Os estudiosos do tema, principalmente da ciência da computação, entendem que os mecanismos de IA são agentes inteligentes, cujo sistema percebe seu ambiente e permite a tomada de atitudes que maximizam as chances de sucesso.

A expressão inteligência artificial foi cunhada em 1956 por John McCarthy, um cientista da computação americano, o qual a definiu como "a ciência e engenharia de produzir máquinas inteligentes". (apud RAJARAMAN, 2014). Portanto, é possível considerar que a IA significa a realização, por uma máquina, de tarefas geralmente ultimadas por seres humanos.

Diversas são as definições as quais também dependem da abordagem de cada autor e sua área de pesquisa. Mas o cerne sempre está nos processos mentais, no raciocínio ou no comportamento humano que está sendo emulado pelo sistema de IA. Conforme Díez, Gómez e Martínez (2001, apud NAVARRO, 2017, p. 23-24) inteligência artificial "es un campo de la ciencia y la ingeniería que se ocupa de la compreensión, desde el punto de vista informático, de lo que se denomina comúmente comportamiento inteligente. También se ocupa de la creación de artefactos que exhiben este comportamiento".

Enfim, dispositivos de IA emulam as diversas capacidades do cérebro humano e se apresentam como máquinas com comportamentos inteligentes que sintetizam e automatizam tarefas intelectuais.

Os professores Coroliano Aurélio de Almeida Camargo e Marcelo Crespo (2016) entendem que a inteligência artificial pode ser dividida em quatro categorias: a aprendizagem mecânica; o processamento da linguagem natural; a visão; e a fala. Explicitam que

\begin{abstract}
a aprendizagem mecânica nada mais é que um sistema que processa dados para melhorar continuamente o desempenho na realização de uma tarefa. Já o processamento da linguagem natural é a possibilidade de um computador compreender a linguagem humana, interpretando o que as pessoas realmente transmitem nas suas interações, decifrando suas intenções e fornecendo respostas cada vez mais precisas nos resultados de uma pesquisa. Já a visão é a habilidade de interpretar imagens, identificá-las e descrevê-las, o que geralmente é feito de forma automática pelos humanos. Por fim, a fala é o sistema que permite uma máquina interpretar a linguagem oral e propiciar interação entre os humanos e as máquinas.
\end{abstract}

Contudo, mesmo com tais definições é muito importante não compreender inteligência artificial apenas através robôs humanoides. Afinal, neste tema, a primeira coisa que vem à cabeça é a ficção científica; os robôs dominando o mundo; ou a robô Sophia que abalou o

Rev. de Direito, Inovação, Propriedade Intelectual e Concorrência | e-ISSN: 2526-0014 | Porto Alegre | v. 4 | n. 2 | p. 1 - 21 | Jul/Dez. 2018 
mundo recentemente quando recebeu cidadania saudita e, em determinadas experiências, relatou que possuía alma própria. (MONTEIRO, 2017). Nem toda IA é humanoide, assim como nem todas as coisas (digitais, conectadas ou analógicas) são inteligentes. É preciso separar o joio do trigo.

Além disso, fala-se em emular o ser humano. Mas será só isso mesmo? Será que as máquinas podem pensar? Essa última pergunta foi proposta por Alan Turing (1950), o qual finalizou sua reflexão dizendo que as máquinas irão competir com os seres humanos em todos os campos intelectuais. E merece destaque o fato de que tal proposição é da década de 50, época em que os computadores estavam no seu início.

Importante é a compreensão de que a IA pode ser fraca ou forte. A fraca é aquela que só consegue fazer aquilo para o que foi programada; já a forte consegue assimilar conteúdos, é versátil na interpretação e tratamento das informações. (MAGRANI, 2018b). Aliás, tal distinção tem relação até mesmo com as diferentes gerações de computadores. Os antigos não tinham capacidade de aprendizado, todas as informações, conclusões e resultados possíveis precisavam ser inseridas na máquina pelo programador. Hoje em dia, um computador pode exercer atividades tal como o cérebro humano. Recebe informações de diversas fontes, de outros computadores, de outros sistemas de IA, para além das informações que possuía ao tempo de sua programação. Da junção de todas as informações e dados recebidos, chega à suas próprias conclusões. (DAVIES, 2011).

O Deep Blue, o sistema de inteligência artificial que venceu Kasparov, o melhor jogador de xadrez do mundo, embora muito avançado, é um exemplo de IA fraca. Ele não consegue jogar dama, só consegue avaliar todas as possibilidades do xadrez. Só consegue fazer aquilo para o que foi programado. O Go - jogo de tabuleiro Chinês - é muito mais complexo que o xadrez, porque possui um número infinito de jogadas. O AlphaGo, sistema de IA da Google, derrotou Ke Jie, o melhor jogador de Go do mundo. Depois disso, o Google criou outra IA que apreendeu a jogar sozinha, e derrotou o próprio AlphaGo. Esses são exemplos de IA forte, assim como o Watson da IBM. IA consegue até mesmo blefar jogando Poker. (MAGRANI, 2018b).

Essas inteligências artificiais fortes, estruturadas pela técnica da aprendizagem profunda (Deep Learning), um ramo do chamado aprendizado de máquinas (Machine Learning), irá levar a humanidade para um nível de desenvolvimento jamais visto porque estão cada vez mais autônomas e imprevisíveis. Os sistemas de IA hoje são capazes de aprender; são capazes de treinar a si próprios através do acúmulo de experiências anteriores próprias e de outros agentes, 
chegando as suas próprias conclusões de forma absolutamente imprevisível. (ČERKAA; GRIGIENĖA; SIRBIKYTE்B, 2015).

Já existem dispositivos autônomos determinando a vida das pessoas. Existem robôs cirurgiões que determinam qual a área afetada pela doença que deve ser removida da pessoa e existem sentenças condenando pessoas à prisão exaradas por inteligências artificiais. (LIPTAK, 2017).

Inteligência artificial, em sentido estrito, seria uma inteligência emulada. A meta no passado era essa. Mas os robôs vão ultrapassar isso, dado que sua capacidade de armazenamento de informação é muito maior. Talvez, tenha que se começar a falar de inteligência computacional. Uma inteligência diferente que não trata apenas de imitar o humano. (MAGRANI, 2018b).

Bom ou ruim? Essencialmente bom, mas é nesse ponto que aparece a importância do ser humano, no sentido de definir o que se quer e o que não se quer destas máquinas inteligentes. E, obviamente, que sempre se exigindo que as decisões tomadas por agentes autônomos sejam explicadas, até em função de uma necessidade de transparência.

Enfim, a simples definição do que se compreende como inteligência artificial, ainda mais na sua modalidade forte, ou quiçá uma inteligência computacional, já permite antever que há um horizonte de discussões sobre questões legais e éticas que deverão ser travadas para que a sociedade possa recepcionar toda esta evolução de modo a utilizar suas potencialidades e se precaver de suas consequências negativas.

\section{DIREITO AUTORAL E INTELIGÊNCIA ARTIFICIAL: COMO FICAM AS OBRAS PRODUZIDAS POR IA?}

Uma das maiores autoridades sobre inteligência artificial da atualidade, o historiador israelense Yuval Harari (2017), em artigo que foi traduzido e publicado pela Revista Veja, intitulado Última Fronteira, afirma que em um futuro não muito distante a inteligência artificial poderá analisar dados biométricos por meio de sensores ligados ao corpo humano para, determinando seu tipo de personalidade e humor no memento, calcular o impacto emocional de uma música em particular, por exemplo. Sugere o autor que o algoritmo será capaz de calcular qual será a música adequada a ser executada em uma situação de alegria, euforia, melancolia ou tristeza. E não é só isso, o algoritmo identificaria que a pessoa pode não gostar de uma parte em particular da música, e assim, poderia ajusta-la, adaptando-a as peculiaridades do ouvinte. 
Nesse ponto, a maravilha da inteligência artificial colocando em xeque tradicionais premissas de propriedade intelectual. Pode a máquina alterar a música de autoria de terceiro sem autorização? Mas, e se o autor concedeu autorização, a música modificada seria uma obra colaborativa resultante da integração entre homem e máquina? Há necessidade de atribuir-se autoria a máquina ou as criações intelectuais das máquinas não possuem um autor e já nascem em domínio público? Veja-se que a eventual desnecessidade de atribuição de autoria não quer dizer, contudo, que as obras não devam ser tuteladas legalmente, até porque as criações intelectuais são motores para o desenvolvimento econômico, social e tecnológico.

Fato é que já existem robôs inteligentes, não necessariamente humanoides, como já se disse, com habilidades para gerar criações intelectuais, independentemente da programação previamente recebida, já que geram resultados autônomos e imprevisíveis, como antes mencionado. Talvez esse agente de inteligência artificial antes noticiado não altere a música existente, mas simplesmente crie uma música levando em consideração o estado de espírito da pessoal ligada ao dispositivo e suas preferências pessoais. E, nesse caso, se poderia falar de uma autoria maquínica?

Existem plataformas digitais baseadas em sistema de IA que criam músicas, a exemplo do Flow Machines, desenvolvido pela Sony. (DE PAULA, 2017). O Aaron é um robô que pinta quadros. (MARTINS, 2014). A tecnologia mudou a forma de as pessoas criarem.

Sérgio Branco (2018) ensina que até o século XX as pessoas estavam presas às criações físicas. A obra (corpus mysticum) dependia do suporte (corpus mechanicum). Não havia foto ou livro sem papel, não havia música sem disco. No século XXI, fortemente impactado pela internet, as inovadoras plataformas de distribuição de fotos, vídeos, músicas e textos não exigem mais o suporte. Pinterest, Instagram, Netflix, Spotfy, além de outros, desmaterializaram as obras autorais. Além disso, a internet também permite a interação entre os usuários, assim como o remix - a modificação das obras - pelos usuários. E não é só isso, estas obras acabam circulando livremente sem indicação de autoria, colocando em xeque o arcabouço tradicional do Direito Autoral. ${ }^{11}$ Portanto, o Direito Autoral já exige reconfiguração de suas categorias jurídicas desde antes e se falar em IA.

\footnotetext{
${ }^{11}$ No mundo digitalizado as indústrias tradicionais perderam o controle de acesso as obras e, portanto, perdem a hegemonia de mercado. Esse repensar do direito autoral é algo absolutamente necessário até como forma de sua sobrevivência, já que a manutenção de uma moldura que já não mais se encaixa na realidade atual só incentiva um posicionamento abolicionista nas novas gerações. É isso que já vem sendo noticiado Lawrence Lessig no Ted Talks, link: https://www.ted.com/talks/larry_lessig_says_the_law_is_strangling_creativity?language=pt-br.
} 
A inteligência artificial pode inclusive auxiliar na criação de conteúdo melhor. Quando um cineasta cria um filme, mesmo que seja brilhante, não está a salvo do fracasso. E um filme fracassado gera um prejuízo financeiro imenso. Foi a partir desta perspectiva que a Netflix investiu em um sistema de IA que afere, por meio de estatística, as preferências dos consumidores e iniciou a produção de séries que são um sucesso estrondoso. House of Cards é o exemplo pioneiro de série de sucesso que foi produzida com base nas informações coletadas pelo sistema de IA da Netflix. (RAMIREZ, 2018).

É bom lembrar que a Lei de Direitos Autorais brasileira determina que para uma obra ser protegida precisa ser original e precisa de um autor, o qual detém controle criativo da obra. Para ser considerada obra precisa do controle criativo do seu autor. Sérgio Branco (2018) exemplifica que na Croácia existe um órgão cuja melodia é criada a partir do impacto das ondas do mar: o Sea Organ em Zadar. O professor entende que esta música está em domínio público porque não há como defender que existe controle criativo pelo autor do órgão.

Define-se, na Lei de Direitos Autorais, que o autor é a pessoa física criadora da obra, literária, artística e científica, bem como define que são obras intelectuais protegidas as criações do espírito, expressas por qualquer meio ou fixadas em qualquer suporte, tangível ou intangível, conhecido ou que se invente no futuro. Não há qualquer dúvida de que as regras legais carregam em si uma visão romântica do Direito Autoral, mas tal visão vem sendo desafiada pelas novas tecnologias.

Outra questão importante é a distinção entre autoria e titularidade da obra, assim como a ressalva em relação à natureza jurídica híbrida dos direitos de autor. $\mathrm{O}$ direito de autor implica na existência de direitos morais, como a paternidade e a integridade da obra, os quais são indisponíveis, apesar de o seu exercício ser transmissível aos herdeiros para o fim de tutela, e em direitos patrimoniais, os quais são resultantes de qualquer forma de exploração econômica da obra. As formas de exploração econômica são disponíveis e transmissíveis, seja entre vivos, através da celebração do contrato de cessão de direitos, seja causa mortis, já que a obra, regra geral, somente cai em domínio público após 70 anos contados de primeiro de janeiro do ano subsequente ao da morte do autor. Essa transmissibilidade dos direitos patrimoniais implica na existência do titular de direito autoral. Portanto, nem sempre o titular do direito é o autor. A titularidade originária é dele, mas poderá ser derivada de negócios jurídicos, da morte, ou até mesmo por determinação legal, o que ocorre com a obra coletiva. (ABRÃO, 2014).

Há pouco tempo ganhou repercussão internacional o caso da selfie da macaca. (LAWSON, 2015). Neste caso em específico, a autoria foi atribuída ao fotógrafo que, embora 
não tenha batido a foto, teve a ideia de deixar sua máquina na floresta para que os macacos sentissem confiança e se aproximassem dos equipamentos para tirar as fotos. Se for isso que realmente aconteceu, o fotógrafo tem o controle criativo sobre a obra mesmo não sendo ele quem disparou a máquina. Seria diferente se a macaca tivesse roubado a máquina e tirado a fotografia de forma involuntária. Nesse caso não haveria controle criativo sobre a foto. $\mathrm{O}$ importante é que o caso reacende a discussão sobre a possibilidade de atribuição de autoria para animais não humanos. Nessa mesma linha está a discussão sobre a autoria da máquina. Quem efetivamente pode ser considerado criador, autor?

Recentemente, uma parceria entre uma universidade e o Museu Rembrandt criaram o projeto "The Next Rembrandt". Toda a obra do autor foi inserida em um sistema de IA, o qual recebeu um comando de que fosse feito um retrato de um homem branco, entre 30 e 40 anos, de barba, com roupas escuras, com colarinho branco, usando um chapéu. Ou seja, usaram os padrões do artista. (IDG, 2018) O resultado, oferecido pelo sistema de AI auxiliado por uma impressora 3D, é impressionante: é um quadro de Rembrandt. A máquina aprendeu a pintar, gerando resultado autônomo, a partir dos padrões inseridos no algoritmo. De quem é a autoria da obra?

Sérgio Branco (2018) explicita que se o quadro foi criado como a música do Sea Organ, não há controle criativo por ninguém, assim a obra não terá autoria. Mas, se os programadores direcionaram os algoritmos, a partir de padrões com controle criativo, poder-seia atender que há autoria. Portanto, defende que a questão principal está em avaliar qual o grau de ingerência de controle criativo dos criadores do programa sobre o produto final para fins de definição de autoria. A partir daí se poderia defender que toda a obra criada por IA nasce em domínio público. Contudo, tal posição implicaria em um desincentivo à criação de obras por IA. Uma solução é atribuir a titularidade da obra ao titular do software, normalmente pessoas jurídicas. Mas essa titularidade derivada apenas resolve a questão patrimonial; não há um autor para desfrutar de seus direitos morais, já que a autoria originária somente poderia ser atribuída às pessoas humanas. Por isso, o autor conclui que para a resolução desse impasse é necessário construir uma nova lógica para os Direitos Autorais, com a reconfiguração de suas categorias jurídicas. Como ressalta Luca Shirru (2016), que também aborda o tema em suas pesquisas, "o arcabouço legal internacional, e principalmente nacional, não está preparado para lidar com situações relacionadas a robôs e inteligência artificial".

Mas, a questão já vem sendo debatida em território europeu. A RoboLaw europeia, uma iniciativa legislativa para adoção de regras em matéria de robótica e IA, trata 
principalmente de questões que envolvem responsabilidade civil e reparação de danos provocados por robôs. Imagine o robô plagiando! Quem responde pelo dano? A resolução do Parlamento Europeu aventa a criação do Estatuto da Pessoa Eletrônica e da figura de uma personalidade eletrônica; ou e-personality. (PEREIRA, 2016; SOUZA, 2018). Em resumo, um robô pode ser sujeito de direito ou não? É possível atribuir personalidade jurídica própria aos robôs, uma personalidade eletrônica? ${ }^{12}$

Há quem defenda que não há que se falar em direito dos robôs, entendendo ser o direito da empresa ou da pessoa física que criou o robô. Há também quem defenda que os robôs podem ser titulares de direitos, principalmente diante do fato de que a máquina exerce capacidade intelectiva, pode efetivamente criar, pode aprender sozinha.

Do ponto de vista do Direito Autoral, o Parlamento Europeu defende que ou será necessário entender que não há Direito Autoral sobre a obra criada e, portanto, a obra estaria em domínio público, ou criar um Direito Autoral autônomo de um robô que é titular de uma personalidade jurídica eletrônica. Volta-se ao ponto do professor Sérgio Branco que entende ser necessária a reconfiguração do Direito Autoral, sob pena de, apenas as questões patrimoniais, serem resolvidas.

Trata-se da verdadeira revolução das máquinas, cuja inteligência está atrelada a um programa de computador. Paradoxal no âmbito das estruturas jurídicas é que alguns países como o Brasil, não protegem os softwares pelo sistema de patentes, já que por lei, os programas de computador em si não são considerados invenções e, nessa medida, não são patenteáveis. (BARBOSA, 2003). Claro que o software embarcado acaba recebendo proteção no conjunto com o hardware, o que acabou se convencionando chamar de patente de software. Contudo muitas dificuldades operacionais ainda são enfrentadas na prática em função das limitações legais. Regra geral, softwares são protegidos pelo direito de autor, mas tal proteção se restringe ao código fonte, não abarcando a sua funcionalidade. (BRANCO; PARANAGUÁ, 2009). Hoje já existe a possibilidade de proteção da funcionalidade através de patentes de métodos ou sistemas implementados por programas de computadores, mas esse ponto não será aqui aprofundado porque exigiria um novo artigo.

\footnotetext{
${ }^{12}$ Pode parecer estranho, mas não é digno de perplexidade. Afinal, a personalidade jurídica atribuída às sociedades, associações e fundações também é uma abstração jurídica e torna estes entes não humanos sujeitos de direitos e obrigações. Claro, não é exatamente a mesma situação quando se imaginam robôs humanoides que podem interagir com humanos, diferentemente de uma sociedade que não possui materialidade alguma. A inciativa europeia sugere a adoção de um registro obrigatório para os robôs e a criação de um seguro para dar conta das hipóteses de danos causados pelos mesmos. (SOUZA, 2018).
}

Rev. de Direito, Inovação, Propriedade Intelectual e Concorrência | e-ISSN: 2526-0014 | Porto Alegre | v. 4 | n. 2 | p. 1-21 | Jul/Dez. 2018 
Um jornalista do The New York Times chegou a anunciar que "os softwares estão comendo o mundo". (ANDREESSEN, 2011). Contudo, de que adianta só enxergar o lado negativo? A tecnologia está posta, não há como voltar atrás.

\section{CONSIDERAÇÕES FINAIS}

É necessário encarar o desafio. Como bem relata o historiador Yuval Harari (2015) (2016), ou nos tornaremos deuses ou seremos extintos pelas nossas próprias invenções. O autor entende que a humanidade passou por duas fases: uma com e outra sem divindades. Transitou de um mundo fundado na noção de Deus, de respeito às leis divinas, para um mundo sem Deus, que é o que acontece durante a revolução científica, a partir do século XVI. Isso não quer dizer que as pessoas não acreditem mais em Deus, mas sim que os fenômenos naturais e a própria existência humana não estão mais fundadas em Deus e passa a ser fundada no que o autor chamou humanismo. Não é mais Deus a medida de todas as coisas, são os homens que dão o sentido para as coisas. Os seres humanos passam a prover as coisas para os outros seres humanos, inclusive compartilhando, trabalhando em conjunto, e dessa forma, passam a ser o alicerce. Mas como tudo é cíclico, o autor entende que este humanismo está fadado a ruir e que isso ocorrerá nesse século. O humanismo será substituído pelo "dadoísmo" ou supremacia dos dados. Nessa fase, não será mais o homem que definirá as coisas, mas os dados, a coleção dos dados ou o big data. $\mathrm{Na}$ época da internet das coisas e da inteligência artificial, os algoritmos vão determinar o comportamento humano, suas escolhas e inclusive o rumo da humanidade. $\mathrm{O}$ autor, na verdade, explica que o ser humano também funciona como uma máquina quando toma uma decisão; ela não decorre de uma escolha consciente, mas é processada por algoritmos internos, biológicos. O julgamento humano é pré-determinado, já que as pessoas são prédeterminadas por uma série de fatores sobre os quais não se tem controle efetivo.

É evidente que a sociedade passa por um momento de transformação intelectual e social, a tecnologia ainda vai mudar muito a relação das pessoas com as coisas e com o mundo em si. De certa forma, esta era, marcada pela supremacia dos dados, é uma consequência de uma nova concepção do que é o ser humano. Na medida em que os dados vão se tornando supremos, o julgamento pessoal deixa de ter relevância e, assim, o próprio ser humano deixa de ter relevância absoluta. As máquinas e a inteligência artificial serão muito mais eficientes que os seres humanos. Os seres humanos tornar-se-iam meros acessórios? Sim ou não, depende de como ele mesmo irá ou não enfrentar as questões postas. Claramente os homens precisarão 
ressignificar a sua própria existência e quiçá repactuar o contrato social de modo a estabelecer uma convivência pacífica com as máquinas inteligentes e as novas estruturas de poder estabelecidas neste contexto.

O uso da tecnologia e da inteligência artificial trará inúmeros benefícios. Tem-se aqui um otimismo como o de Mark Zuckerberg. Mas não se pode deixar de concordar com Elon Musk que será necessário regulamentar o seu uso, evitando que venha a prejudicar o ser humano. E essa regulamentação não necessariamente exige iniciaria legislativa, também pode se dar através de autorregulamentação, a exemplo do Asilomar AI Principles ${ }^{13}$, que definem princípios éticos e valores que devem nortear o desenvolvimento de AI.

Dentro desse contexto macro, está o micro mundo do Direito Autoral, e não só ele, mas todo o Direito da Propriedade Intelectual, o qual exige também uma reconfiguração para adequar-se a essa nova realidade. Enquanto a legislação determina que somente a pessoa humana possa ser autora e que as obras são criações do espírito, de duas uma: ou as obras criadas por IA estão em domínio público, ou será atribuída a titularidade sobre a mesma para alguém explorar seus potenciais frutos econômicos. Mas nesse caso, como já constatado, os direitos morais ficam órfãos.

A reconfiguração de categorias jurídicas é necessária. Afinal, a sociedade está sempre em transformação. Já dizia Rilke no clássico "Cartas a um jovem Poeta”: "o futuro nos invade... a fim de, dentro da gente, transforam-se antes mesmo de ocorrer".

\section{REFERÊNCIAS}

ABRÃO, Eliane Yachouh. Direitos de autor e direitos conexos. 2.ed. rev. e ampl. São Paulo: Migalhas, 2014.

ANDREESSEN, Marc. Why Software Is Eating The World?. The Wall Street Journal. Ago., 2011.

Disponível

em: https://www.wsj.com/articles/SB10001424053111903480904576512250915629460, acesso em 28 out. 2017.

ATENIENSE, Alexandre. A Inteligência artificial e o Direito: Como a computação cognitiva impactará nas atividades dos profissionais do Direito. Jusbrasil. Jun., 2017. Disponível em: https://alexandre-atheniense.jusbrasil.com.br/artigos/467690643/a-inteligencia-artificial-e-odireito, acesso em 25 out. 2017.

\footnotetext{
${ }^{13}$ Os princípios foram desenvolvidos na Conferência em Asilomar, nos EUA, em 2017. Para conferir, use o link: https://futureoflife.org/ai-principles/.
} 
BARBOSA, Denis Borges. Propriedade Intelectual: direitos autorais, direitos conexos e software. Rio de Janeiro: Lumen Juris, 2003.

BRANCO, Sérgio. Inteligência Artificial e Produção Cultural. ITS Rio. Abr. 2018. Curso "Inteligência artificia: (r)evolução na prática" ministrado on line.

ČERKAA, Paulius; GRIGIENĖA, Jurgita; SIRBIKYTĖB, Gintarè. Liability for damages caused by artificial intelligence. Computer Law \& Security Review. Vol 31. No.3. Jun., 2015.

CHRISTENSEN, Clayton M. O Dilema da Inovação: quando as novas tecnologias levam empresas ao fracasso. São Paulo: M. Books, 1997.

De mãos dadas com a inteligência artificial. Revista Veja. Ed. 2549, ano 50, nº 39, Set., 2017.

DAVIES, Colin R. An evolutionary step in intellectual property rights: Artificial Intelligence and Intellectual Property. Computer Law \& Security Review. Vol 27. P. 601-619. Dec., 2011.

DE PAULA, Alexandre. Plataforma de inteligência artificial agora compõe música brasileira. Correio Braziliense. Out., 2017. Disponível em: http://www.correiobraziliense.com.br/app/noticia/diversao-earte/2017/10/03/interna_diversao_arte,630839/plataforma-de-inteligencia-artificial-agoracompoe-musica-brasileira.shtml, acesso em 20 out. 2017.

DONEDA, Danilo. Da privacidade à proteção de dados pessoais. Rio de Janeiro: Renovar, 2006.

EDGELL, Stephen. The sociology of work: continuity and change in paid and unpaid work. Sage Publications, 2012.

Europa ocupa-se do estatuto jurídico dos robôs. RTP Notícias. Jan., 2017. Disponível em: https://www.rtp.pt/noticias/fronteiras-xxi/europa-ocupa-se-do-estatuto-juridico-dos-

robos_n975419, acesso em 22 out. 2017.

FERNANDES, Edson Carlos. O advogado mais inteligente da cidade. GEJUR - Gestão Jurídica Empresarial. Mai., 2017. Disponível em: https://www.intelijur.com.br/gejur/noticias/artigos/o-advogado-mais-inteligente-da-cidade, acesso em 30 set. 2017.

GENTILE, Fábio da Rocha. Advocacia artificial, meu caro Watson? Análise da inserção da inteligência artificial no universo da advocacia. Jota. Abr., 2017. Disponível em: https://jota.info/artigos/advocacia-artificial-meu-caro-watson-01042017, acesso em 31 out. 2017.

HARADA, Eduardo. Fail épico: sistema do Google Fotos identifica pessoas negras como gorilas. Tecmundo. 01 jul. 2015. Disponível em: https://www.tecmundo.com.br/googlefotos/82458-polemica-sistema-google-fotos-identifica-pessoas-negras-gorilas.htm, acesso em 04 ago. 2018.

HARARI, Yuval Noah. Sapiens: uma breve história da humanidade. São Paulo: Companhia das Letras, 2015.

Homo Deus: uma breve história do amanhã. São Paulo: Companhia das Letras, 2016.

Rev. de Direito, Inovação, Propriedade Intelectual e Concorrência | e-ISSN: 2526-0014 | Porto Alegre | v. 4 | n. 2 | p. 1 - 21 | Jul/Dez. 2018 
Inteligência artificial e impressora 3D criam novo quadro de Rembrandt. IDG News Service. 8. Abr., 2016. Disponível em: http://idgnow.com.br/internet/2016/04/08/inteligencia-artificiale-impressora-3d-criam-novo-quadro-de-rembrandt//pagina-impressao, acesso em 04 ago. 2018.

Justiça decide que selfie tirada por macaco pertence ao fotógrafo. O Globo. Set., 2017. Disponível em: https://oglobo.globo.com/sociedade/justica-decide-que-selfie-tirada-pormacaco-pertence-fotografo-1-21810919, acesso em 15 de outubro de 2017.

KLEINA, Nilton. A história da Kodak, a pioneira da fotografia que parou no tempo. Tecmundo. 10 out. 2017. Disponível em: https://www.tecmundo.com.br/mercado/122279historia-kodak-pioneira-da-fotografia-nao-evoluiu-video.htm, acesso em 20 out. 2017.

LAWSON, Alastair. Selfie de macaco vira alvo de disputa sobre direitos autorais. BBC News. Set., 2015.2 Disponível em: http://www.bbc.com/portuguese/noticias/2015/09/150926_selfie_macaco_polemica_lgb, acesso em 15 out. 2017.

LIPTAK, Adam. Sent to Prison by a Software Program's Secret Algorithms. The New York Times. 1 mai. 2017. Disponível em: https://www.nytimes.com/2017/05/01/us/politics/sent-toprison-by-a-software-programs-secret-algorithms.html, acesso em 2 ago. 2018.

LUHMANN, Niklas. Sociologia do Direito I. Rio de Janeiro: Tempo Brasileiro, 1983.

MAGRANI, Eduardo. A internet das coisas. Rio de Janeiro: FGV, 2018a.

Inteligência Artificial: o que é e como ela pode afetar sua vida. ITS Rio. Abr. 2018b. Curso "Inteligência artificia: (r)evolução na prática" ministrado on line.

MARTINS, Beatriz Cintra. Aaron - um software artista? Autoria em Rede. Dez., 2014. Disponível em: https://autoriaemrede.wordpress.com/2014/01/16/aaron-um-software-artista/, acesso em 20 de outubro de 2017.

MONTEIRO, Rafael. Robô que "queria destruir humano" ganha cidadania saudita. GQ Globo. 27 out., 2017. Disponível em: https://gq.globo.com/Prazeres/Tecnologia/noticia/2017/10/roboque-queria-destruir-humanos-ganha-cidadania-saudita.html, acesso em 02 de agosto de 2018.

NAVARRO, Susana Navas. Inteligencia artificial, tecnología, derecho. Valência: Tirant lo Blanch, 2017.

NEGROPONTE, Nicholas. A vida digital. Traduzido por Sérgio Tellaroli. São Paulo: Companhia das letras, 1995.

PALAZUELOS, Félix. Elon Musk: "A inteligência artificial ameaça a existência da nossa civilização". El País. Jul. $2017 . \quad$ Disponível em: https://brasil.elpais.com/brasil/2017/07/17/tecnologia/1500289809_008679.html, acesso em 02 ago. 2018.

PARISER, Eli. O Filtro Invisível: o que a internet está escondendo de você. São Paulo: Zahar, 2012.

PARANAGUÁ, Pedro; BRANCO, Sérgio. Direitos Autorais. Rio de Janeiro: FGV, 2009.

Rev. de Direito, Inovação, Propriedade Intelectual e Concorrência | e-ISSN: 2526-0014 | Porto Alegre | v. 4 | n. 2 | p. 1 - 21 | Jul/Dez. 2018 
PEREIRA, Leonardo. Parlamento Europeu quer classificar robôs como "pessoas eletrônicas". Olhar Digital. Jun., 2016. Disponível em: https://olhardigital.com.br/pro/noticia/parlamentoeuropeu-quer-classificar-robos-como-pessoas-eletronicas/59571, acesso em 22 out. 2017.

PEREIRA, Tibério. Como a Inteligência Artificial (IA) está mudando radicalmente a vida na Terra. Linkedin. 12 mar. 2017. Disponível em: https://pt.linkedin.com/pulse/comointelig\%C3\%AAncia-artificial-ia-est\%C3\%A1-mudando-vida-na-terra-pereira, acesso em 20 out. 2017.

PISTONO, Federico. Os robôs vão roubar o seu trabalho, mas tudo bem. Traduzido por Pedro Soares. São Paulo: Portfolio Pinguin, 2017.

RAJARAMAN, V. John McCarthy - Father of Artificial Intelligence. Asia Pacific Mathematics Newsletter. Jul. 2014, v. 4, $\mathrm{n}^{\mathrm{o}}$ 3, p. 15-20. Disponível em: http://www.asiapacific-mathnews.com/04/0403/0015_0020.pdf, acesso em 20 out. 2017.

RAMÍREZ, Vicente. House Of Cards: el éxito que Netflix creó gracias a la inteligencia artificial ¿Cómo ha utilizado Netflix la inteligencia artificial para crear una serie en base a tus gustos? BigData Magazine. 7 mar., 2018. Disponível em: https://bigdatamagazine.es/house-of-cardsel-exito-que-netflix-creo-gracias-a-la-inteligencia-artificial, acesso em 4 ago. 2018.

SANTOS, Coriolano Aurélio de Almeida Camargo; CRESPO, Marcelo. Inteligência artificial, tecnologia e o Direito: o debate não pode esperar!. Migalhas. Jun. 2016. Disponível em: http://www.migalhas.com.br/DireitoDigital/105,MI249734,41046-

Inteligencia+artificial+tecnologia+e+o+Direito+o+debate+nao+pode, acesso em 20 out. 2017.

SCHWAB, Klaus. A quarta revolução industrial. Traduzido por Daniel Moreira Miranda. São Paulo: Edipro, 2016.

SHIRRU, Luca. A Inteligência Artificial e o Direito Autoral: primeiras reflexões e problematizações. Boletim GEDAI. 09 fev., 2016.2 Disponível em: http://www.gedai.com.br/?q=pt-br/boletins/boletim-gedai-agosto-2016/intelig\%C3\%AAnciaartificial-e-o-direito-autoral-primeiras-reflex\%C3\%B5es-e, acesso em 3 ago. 2018.

SÔNEGO, Dubes. Tudo bem para quem? Revista Época, ano 11, nº 128, out., 2017.

SOUZA, Carlos Affonso. O debate sobre a personalidade jurídica para robôs: errar é humano, mas o que fazer quando também for robético? Jota. 10 out., 2017. Disponível em: https://www.jota.info/opiniao-e-analise/artigos/o-debate-sobre-personalidade-juridica-pararobos-10102017, acesso em 4 ago. 2018.

TEUBNER, Gunther. Fragmentos constitucionais: constitucionalismo social na globalização. São Paulo: Saraiva, 2016.

TURING, Alan M. Computing Machinery and Intelligence. Mind. Vol. 49. 1950.

Why scientists must work together to save the world. Interdisciplinarity, Nature News. Vol. 525, $17 \quad$ set., 2015.2 Disponível em: https://www.nature.com/polopoly_fs/1.18370!/menu/main/topColumns/topLeftColumn/pdf/5 25305a\%20corrected.pdf, acesso em 3 nov. 2017. 